\title{
Meta-analysis of short-acting insulin analogues in adult patients with type 1 diabetes: continuous subcutaneous insulin infusion versus injection therapy
}

\author{
A. Siebenhofer ${ }^{1}$ J. Plank ${ }^{1}$ A. Berghold ${ }^{2}$ K. Horvath ${ }^{1}$ P. T. Sawicki ${ }^{3}$ P. Beck ${ }^{4}$ - T. R. Pieber ${ }^{1,4}$ \\ ${ }^{1}$ Division of Diabetes and Metabolism, Department of Internal Medicine, Medical University, \\ Leopold Auenbrugger University Hospital, Graz, Austria \\ 2 Institute for Medical Informatics, Statistics and Documentation, Medical University, Graz, Austria \\ ${ }^{3}$ Department of Internal Medicine, St. Franziskus Hospital and Institute for Evidence-based Medicine, Cologne, Germany \\ ${ }^{4}$ Joanneum Research, Institute of Medical Technologies and Health Management, Graz, Austria
}

\begin{abstract}
Aims/hypothesis. This study aimed to compare the effect of treatment with short-acting insulin (SAI) analogues versus structurally unchanged short-acting insulin (regular insulin) on glycaemic control and on the risk of hypoglycaemic episodes in type 1 diabetic patients using different insulin treatment strategies.

Methods. We performed a meta-analysis of 27 randomised controlled trials that compared the effect of SAI analogues with regular insulin in patients with type 1 diabetes mellitus. The treatments were administered either via continuous subcutaneous insulin infusion (CSII) or by conventional intensified insulin therapy (IIT) with short-acting insulin injections before meals and basal insulin administered once or twice daily in most cases.

Results. $\mathrm{HbA}_{1} \mathrm{c}$ levels were reported for 20 studies. For studies using CSII, the weighted mean difference between values obtained using SAI analogues and regular insulin was $-0.19 \%$ (95\% CI: -0.27 to 0.12 ), whereas the corresponding value for injection
\end{abstract}

studies was $-0.08 \%$ (95\% CI: -0.15 to -0.02 ). For the analysis of overall hypoglycaemia, we used the results from nine studies that reported the mean frequency of hypoglycaemic episodes per patient per month. For studies using CSII, the standardised mean difference between SAI analogues and regular insulin was -0.07 (95\% CI: -0.43 to 0.28$)$, whereas for IIT studies the corresponding value was -0.04 (95\% CI: -0.24 to 0.16 ).

Conclusions/interpretation. Taking into consideration the low quality of the trials included, we can conclude that use of a short-acting insulin analogue in CSII therapy provides a small, but statistically significant improvement in glycaemic control compared with regular insulin. An even smaller effect was obtained with the use of ITT. The rate of overall hypoglycaemic episodes was not significantly reduced with short-acting insulin analogues in either injection regimen.

Keywords Complications - Continuous subcutaneous insulin infusion - Diabetes mellitus - Hypoglycaemia . Intensified insulin therapy · Meta-analysis · Randomised controlled trial
Received: 29 January 2004 / Accepted: 19 April 2004 Published online: 25 November 2004

(C) Springer-Verlag 2004

\section{A. Siebenhofer $(\square)$}

Division of Diabetes and Metabolism,

Department of Internal Medicine, Medical University,

Leopold Auenbrugger University Hospital,

Auenbruggerplatz 15, 8036 Graz, Austria

E-mail: andrea.siebenhofer@uni-graz.at

Tel.: +43-316-3853270, Fax: +43-316-3854332
Abbreviations: CSII, continuous subcutaneous insulin infusion · IIT, conventional intensified insulin therapy · SAI, short-acting insulin

Conflict of interest statement: A. Siebenhofer, J. Plank, K. Horvath, T.R. Pieber performed clinical trials on short- and long-acting insulin analogues with the companies Aventis, Eli Lilly and Novo Nordisk. T.R. Pieber was or is a currently paid consultant for these companies. T.R. Pieber is on the advisory board of Novo Nordisk. 


\section{Introduction}

It is difficult to achieve day-long normoglycaemia using structurally unchanged short-acting insulin (regular insulin) preparations [1] because regular insulin tends to associate in 'clusters' of six molecules (hexamers), and these clusters take time after injection to dissociate into single molecules that can be used by the body [2]. The dissociation of hexamers is facilitated in short-acting insulin analogues (SAI analogues), and these achieve peak plasma concentrations about twice as high and within approximately half the time compared with regular insulin $[3,4]$. Despite the theoretical superiority of SAI analogues over regular insulin, the efficacy of SAI analogues in the treatment of diabetic patients is still unclear. Some studies have reported improved metabolic control and reduced hypoglycaemic episodes $[5,6,7,8,9,10,11,12,13]$, whereas others failed to show a positive effect $[14,15$, $16]$.

In this study we performed a systematic review and meta-analysis of studies that compared SAI analogues with regular insulin either in continuous subcutaneous insulin infusion (CSII) or intensified insulin therapy (IIT) according the Quality of Reporting of Metaanalyses (QUOROM) statement [17] of controlled and randomised trials. This was carried out in order to evaluate the possible advantages of SAI analogues in terms of glycaemic control and the numbers of overall and severe hypoglycaemic episodes.

\section{Subjects and methods}

Identification and selection of trials. We performed a highly sensitive search for randomised controlled trials combined with key terms for identifying studies comparing SAI analogues with regular insulin using the Cochrane Library (issue 4, 2003) [18], Medline (1966 to December 2003), Embase (1974 to December 2003). We also hand-searched reference lists and abstract books from major diabetology meetings from 1992 to 2003, contacted the three main pharmaceutical companies (Aventis [Strasbourg, France], Eli Lilly [Indianapolis, Ind., USA], Novo Nordisk [Bagsvaerd, Denmark]) and checked textbooks and bibliographies. Forty-seven authors and experts were contacted, and $16(34 \%)$ responded to our queries.

All randomised controlled trials in which adult type 1 diabetic patients (excluding pregnant women and children) receiving the two SAI analogue treatments available on the market (aspart, lispro) were compared with patients receiving regular insulin treatment were considered. Intervention duration had to be 4 weeks or more, and insulin had to be injected subcutaneously either via CSII or IIT with short-acting insulin before meals. Studies in which any additional treatment was given were included as long as this was administered equally to both groups.

Outcome measures. We assessed glycaemic control measured by percentage of $\mathrm{HbA}_{1} \mathrm{c}$ and numbers of overall and severe hypoglycaemic episodes. Table 1 describes the classification and threshold blood glucose levels for hypoglycaemia. The heterogeneity of reporting only allowed a statistical analysis of overall hypoglycaemic events to be made.

Study selection, collection and quality assessment. Two reviewers independently screened the title, abstract and keywords of each reference identified by the search. Where there were differences of opinion, these were resolved by a third party. Only full papers were considered for the systematic review. Data from each study included were extracted by the two independent reviewers using a structured data extraction form. The methodological quality of each trial was assessed using modifications of the criteria given in the Cochrane Handbook and the criteria of Jadad [19] and Schulz [20]. We used three categories such that assessment A means that plausible bias is unlikely to seriously affect the results, assessment B means that plausible bias raises some doubt about the results and assessment $\mathrm{C}$ means that plausible bias seriously weakens confidence in the results.

Statistical analysis. Weighted mean differences were calculated for the percentage of glycosylated haemoglobin, and a random effects model was used for the meta-analysis.

We tried to incorporate the two different study designs used (crossover and parallel) into the meta-analysis [21, 22]. One of the prerequisites for using a crossover study is that the mean difference (or the difference between means) of the treatments is available. Additionally, the standard deviation, standard error or a confidence interval for the within-person differences must be given. These estimates were provided for some of the studies, whereas for other studies we had to estimate the SE from the test statistic or from $p$ values. In cases where the SE for the within-person differences could not be extracted from a trial, the correlation between treatment outcomes was approximated using the lowest observed correlation among the other studies $(r=0.69)$. The robustness of the results was assessed by repeating the analysis using a fixed-effects model. Heterogeneity between trials was assessed by the chi square test. A funnel plot and Egger's test were used to test for publication bias. The standardised mean difference was calculated for overall hypoglycaemic episodes per patient per month using unpaired analysis. The number of severe hypoglycaemic episodes per 100 patient-years was calculated by dividing the number of severe hypoglycaemic episodes by the years of exposure and then multiplying by 100 .

This manuscript presents part of the results of a systematic review "Short acting insulin analogues versus regular human insulin in patients with diabetes mellitus" by the Metabolic and Endocrine Disorders Group of the Cochrane Collaboration, which will be published in the Cochrane Library (issue 2, 2004).

\section{Results}

The initial search using the search strategy described yielded 1143 studies. After initial investigation of the abstracts, 1071 articles were excluded by consensus. There were differences of opinion on four further articles, and these were resolved by a third party; three were excluded and one was included in the analysis. Therefore, 69 randomised controlled trials were potentially appropriate for inclusion in the meta-analysis (Fig. 1). 
Table 1. Characteristics of the different randomised controlled trials

\begin{tabular}{|c|c|c|c|}
\hline Study & Methods & Participants / interventions & Definition of hypoglycaemia \\
\hline \multicolumn{4}{|l|}{ CSII studies } \\
\hline Bode 2001 [38] & $\begin{array}{l}\text { Design: parallel } \\
\text { Follow-up: } 49 \text { days } \\
\text { Q-assessment: C } \\
\text { Sponsor: Novo Nordisk }\end{array}$ & $\begin{array}{l}\text { Aspart vs. Regular } \\
19 \text { vs } 10 \text { Type } 1 \text { diabetic patients } \\
\text { Mean age: } 38 \text { vs } 34 \text { years } \\
\text { Diabetes duration: unknown }\end{array}$ & $\begin{array}{l}\text { Overall: }<2.5 \mathrm{mmol} / 1 \text { without } \\
\text { an appropriate explanation } \\
\text { Severe: } \text { not defined }\end{array}$ \\
\hline Johansson 2000 [5] & $\begin{array}{l}\text { Design: crossover } \\
\text { Follow-up: } 120 \text { days } \\
\text { Q-assessment: B } \\
\text { Sponsor: Eli Lilly }\end{array}$ & $\begin{array}{l}\text { Lispro vs Regular } \\
41 \text { Type } 1 \text { diabetic patients } \\
\text { Mean age: } 42 \text { years } \\
\text { Diabetes duration: } 21 \text { years }\end{array}$ & $\begin{array}{l}\text { Overall: }<3 \mathrm{mmol} / 1 \text { and/or symptoms } \\
\text { Severe: } \text { third-party help }\end{array}$ \\
\hline Renner 1999 [6] & $\begin{array}{l}\text { Design: crossover } \\
\text { Follow-up: } 240 \text { days } \\
\text { Q-assessment: C } \\
\text { Sponsor: Eli Lilly }\end{array}$ & $\begin{array}{l}\text { Lispro vs Regular } \\
113 \text { Type } 1 \text { diabetic patients } \\
\text { Mean age: } 37 \text { years } \\
\text { Diabetes duration: } 19 \text { years }\end{array}$ & $\begin{array}{l}\text { Overall: }<3.5 \mathrm{mmol} / 1 \text { and/or symptoms } \\
\text { Severe: not defined }\end{array}$ \\
\hline Schmauss 1998 [15] & $\begin{array}{l}\text { Design: crossover } \\
\text { Follow-up: } 180 \text { days } \\
\text { Q-assessment: C } \\
\text { Sponsor: Eli Lilly }\end{array}$ & $\begin{array}{l}\text { Lispro vs Regular } \\
11 \text { Type } 1 \text { diabetic patients } \\
\text { Mean age: } 30 \text { years } \\
\text { Diabetes duration: } 14 \text { years }\end{array}$ & $\begin{array}{l}\text { Overall: }<3.5 \mathrm{mmol} \text { and/or symptoms } \\
\text { Severe: i. v. glucagon or glucose }\end{array}$ \\
\hline Zinman 1997 [40] & $\begin{array}{l}\text { Design: crossover } \\
\text { Follow-up: } 180 \text { days } \\
\text { Q-assessment: C } \\
\text { Sponsor: Eli Lilly }\end{array}$ & $\begin{array}{l}\text { Lispro vs Regular } \\
30 \text { Type } 1 \text { diabetic patients } \\
\text { Mean age: } 35 \text { years } \\
\text { Diabetes duration: } 18 \text { years }\end{array}$ & $\begin{array}{l}\text { Overall: }<3 \mathrm{mmol} / 1 \text { and/or symptoms } \\
\text { Severe: } \text { third-party help }\end{array}$ \\
\hline \multicolumn{4}{|l|}{ IIT studies } \\
\hline Anderson 1997 [8] & $\begin{array}{l}\text { Design: parallel } \\
\text { Follow-up: } 360 \text { days } \\
\text { Q-assessment: C } \\
\text { Sponsor: Eli Lilly }\end{array}$ & $\begin{array}{l}\text { Lispro vs Regular } \\
336 \text { Type } 1 \text { diabetic patients } \\
\text { Mean age: } 32 \text { years } \\
\text { Diabetes duration: } 13 \text { years } \\
\underline{295 \text { Type } 2 \text { diabetic patients }} \\
\quad \text { (not analysed) }\end{array}$ & $\begin{array}{l}\text { Overall: }<2 \mathrm{mmol} / \mathrm{l} \text { and/or symptoms } \\
\text { Severe: not defined }\end{array}$ \\
\hline Anderson 1997 [12] & $\begin{array}{l}\text { Design: crossover } \\
\text { Follow-up: } 180 \text { days } \\
\text { Q-assessment: C } \\
\text { Sponsor: Eli Lilly }\end{array}$ & $\begin{array}{l}\text { Lispro vs Regular } \\
1008 \text { Type } 1 \text { diabetic patients } \\
\text { Mean age: } 33 \text { years } \\
\text { Diabetes duration: } 12 \text { years }\end{array}$ & $\begin{array}{l}\text { Overall: }<3.5 \mathrm{mmol} / 1 \text { and/or symptoms } \\
\text { Severe: third-party help }\end{array}$ \\
\hline $\begin{array}{l}\text { Del Sindaco } 1998 \\
\text { [11] }\end{array}$ & $\begin{array}{l}\text { Design: } 4 \text { groups, } \\
\quad \text { crossover } \\
\text { Follow-up: } 180 \text { days } \\
\text { Q-assessment: C } \\
\text { Sponsor: not defined }\end{array}$ & $\begin{array}{l}\text { I: lispro vs regular + NPH once } \\
\text { or twice daily } \\
\text { II: lispro vs regular } \\
\quad+\text { NPH } 4 \text { times daily } \\
\text { I: } 15 \text {; II: } 12 \text { Type } 1 \text { diabetic patients } \\
\text { Mean age: I: } 33 \text {; II: } 32 \text { years } \\
\text { Diabetes duration: I: } 15 \text {; II: } 13 \text { years }\end{array}$ & $\begin{array}{l}\text { Overall: }<3.3 \mathrm{mmol} / 1 \\
\text { Severe: third-party help }\end{array}$ \\
\hline Ferguson 2001 [41] & $\begin{array}{l}\text { Design: crossover } \\
\text { Follow-up: } 336 \text { days } \\
\text { Q-assessment: C } \\
\text { Sponsor: Eli Lilly }\end{array}$ & $\begin{array}{l}\text { Lispro vs Regular } \\
39 \text { Type } 1 \text { diabetic patients } \\
\text { Mean age: } 46 \text { years } \\
\text { Diabetes duration: } 26 \text { years }\end{array}$ & $\begin{array}{l}\text { Overall: }<3.5 \mathrm{mmol} / 1 \text { and/or symptoms } \\
\text { Severe: third-party help }\end{array}$ \\
\hline
\end{tabular}


Table 1 (continued)

\begin{tabular}{ll}
\hline Study & Methods \\
\hline Gale 2000 [16] & Design: crossover \\
& Follow-up: 168 days \\
& Q-assessment: C \\
& Sponsor: Eli Lilly \\
& Design: crossover \\
Heller 1999 [42] & Follow-up: 240 days \\
& Q-assessment: B \\
& Sponsor: Eli Lilly
\end{tabular}

Holleman 1997 [10] Design: crossover Follow-up: 84 days $Q$-assessment: C Sponsor: Eli Lilly

Home 1998 [43]

Design: crossover Follow-up: 56 days $Q$-assessment: C Sponsor: Novo Nordisk

Home 2000 [44] Design: parallel Follow-up: 180 days $Q$-assessment: C Sponsor: Novo Nordisk

Iwamoto 2001 [45] Design: parallel Follow-up: 168 days Q-assessment: C Sponsor: Novo Nordisk

$\begin{array}{ll}\text { Provenzano 2001 } & \text { Design: crossover } \\ & \text { Follow-up: } 336 \text { days } \\ & \text { Q-assessment: C } \\ & \text { Sponsor: not defined } \\ \text { Raskin 2000 [49] } & \text { Design: parallel } \\ & \text { Follow-up: } 180 \text { days } \\ & \text { and } 180 \text { days extens } \\ & \text { Q-assessment: C } \\ & \text { Sponsor: Novo Nordisk } \\ & \text { Design: crossover } \\ \text { Vignati 1997 [52] } & \text { Follow-up: } 120 \text { days } \\ & \text { Q-assessment: C } \\ & \text { Sponsor: Eli Lilly }\end{array}$

Ciofetta 1999 [47] Design: parallel Follow-up: 90 days Q-assessment: C Sponsor: No sponsor

Annuzzi 2001 [48] Design: crossover Follow-up: 180 days Q-assessment: C Sponsor: Eli Lilly

Roach 1999 [51]

Design: crossover Follow-up: 180 days $Q$-assessment: C Sponsor: Eli Lilly

Lispro vs Regular

93 Type 1 diabetic patients

Mean age: 35 years

Diabetes duration: 13 years

Lispro vs Regular

68 vs 67 Type 1 diabetic patients

Mean age: 37 vs 39 years

Diabetes duration: 16 vs 17 years

Lispro vs Regular 199 Type 1 diabetic patients Mean age: 35 years

Diabetes duration: 13 years

Aspart vs Regular

104 Type 1 diabetic patients

Mean age: 34 years

Diabetes duration: 15 years

Aspart vs. Regular

707 vs 358 Type 1 diabetic patients

Mean age: 38 years

Diabetes duration: 15 years

Aspart vs Regular

143 vs 64 Type 1 diabetic patients

Mean age: 34 vs 32 years

Diabetes duration: 11 years

Lispro vs Regular

12 Type 1 diabetic patients

Mean age: 28 years

Diabetes duration: 12 years

Aspart vs Regular

596 vs 286 Type 1 diabetic patients

Mean age: 39 vs 40 years

Diabetes duration: 16 years

Lispro vs Regular

379 Type 1 diabetic patients

Mean age: 39 years

Diabetes duration: 13 years

328 Type 2 diabetic patients (not analysed)

Lispro vs Regular

16 Type 1 diabetic patients

Mean age: 33 years

Diabetes duration: 13 years

Lispro vs Regular

90 Type 1 diabetic patients

Mean age: 31 years

Diabetes duration: 12 years

Lispro vs Regular

37 Type 1 diabetic patients

Mean age: 40 years

Diabetes duration: 13 years

63 Type 2 diabetic patients (not analysed)
Definition of hypoglycaemia

Overall: $<2.5 \mathrm{mmol} / \mathrm{l}$ and/or symptoms

Severe: coma and/or i. v. glucose or glucagon

Overall: $<3 \mathrm{mmol} / \mathrm{l}$ and /or symptoms Severe: third-party help

Overall: $<3 \mathrm{mmol} / \mathrm{l}$ and/or symptomatic Severe: third-party help

Overall: symptoms

Severe: third-party help

Overall: symptoms

Severe: third-party help

Overall: symptoms

Severe: not defined

Overall: symptoms

Severe: glucagon, glucose, coma

Overall: $<2.5 \mathrm{mmol} / \mathrm{l}$ and/or symptoms Severe: third-party help

Overall: $<3.5 \mathrm{mmol} / 1$

Severe: glucagon

Overall: $<3.9 \mathrm{mmol} / 1$

Severe: third-party help

Overall: $<3.3 \mathrm{mmol} / 1$ and/or symptoms Severe: third-party help

Overall: $<3 \mathrm{mmol} / \mathrm{l}$ and/or symptoms Severe: coma, i. v. glucagon or glucose 
Table 1 (continued)

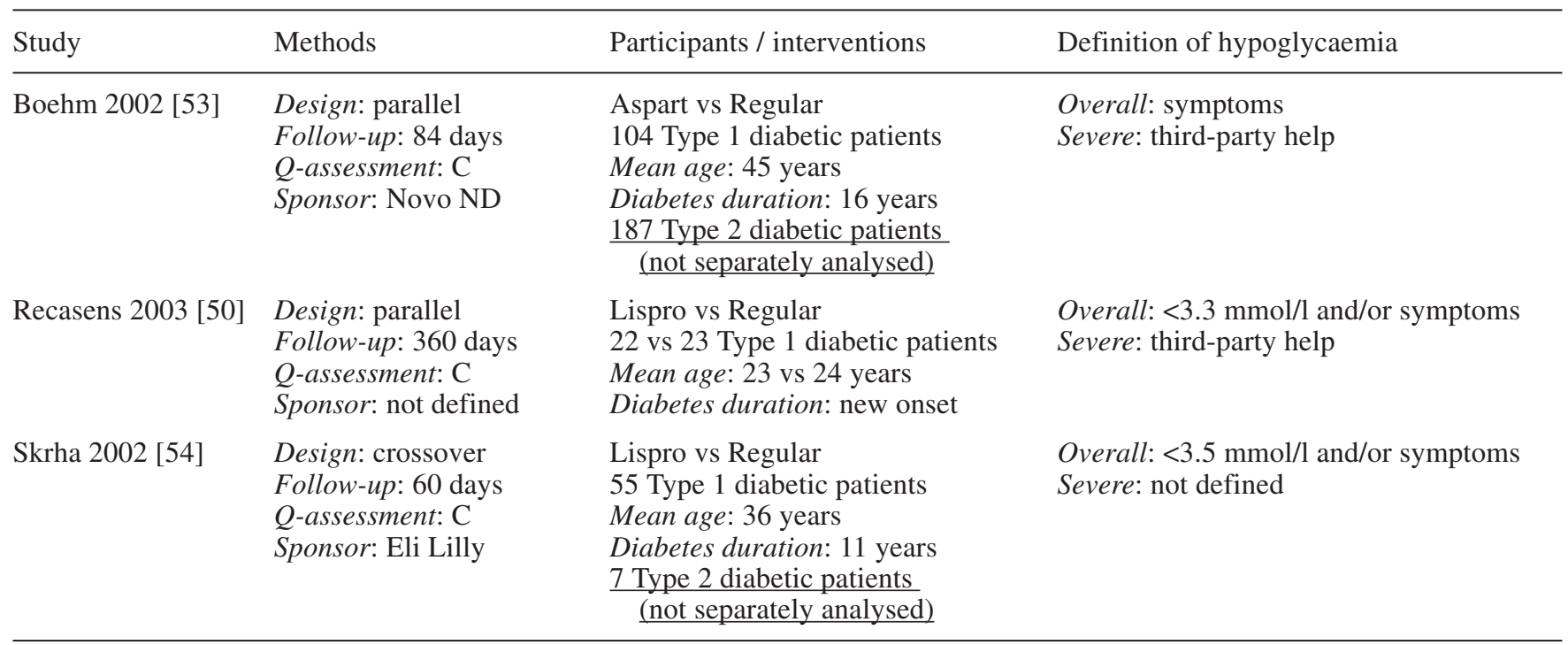

NPH: neutral protamine Hagedorn insulin; Q-assessment, quality assessment

Twenty-seven studies were excluded upon further scrutiny. The main reasons for exclusion were: (i) interventions not comparable; (ii) partial and duplicate publications of a multicentre study; (iii) study duration of less than 4 weeks; or (iv) reporting of data for only one study period. A further 15 studies were excluded from this analysis. Of these, five were performed with patients with type 2 diabetes [23, 24, 25, $26,27]$, three were performed with children [28, 29, $30]$, one with adolescents [31], one with children and adults [32], one with pregnant type 1 diabetic patients [33], two with patients with gestational diabetes [34, 35] and two duplicate publications did not provide further information on prespecified outcome measures $[36,37]$. We ultimately identified 27 randomised controlled trials that compared SAI analogues with regular insulin using either CSII or IIT as injection regimens. Of these, 22 studies were performed with type 1 diabetic patients $[5,6,7,10,11,12,14,15,16,38,39$, $40,41,42,43,44,45,46,47,48,49,50]$ and five studies had a combined study population of type 1 and type 2 diabetic patients [8, 51, 52, 53, 54].

Table 1 summarises the characteristics of the trials included in our analysis. The comprehensive data collection sheet is available from the authors. Of the eight trials in which CSII was used, six had a crossover design and two had a parallel design. A total of 707 subjects took part in the CSII trials. The unweighted mean age was 39 years for patients treated with SAI analogues and 38 years for patients treated with regular insulin. Diabetes duration was 20 years for both treatment groups. Trial duration ranged from 42 to 120 days, with a mean follow-up period of 84 days. The quality of six studies was assessed to be in category C. Two studies were of higher quality (category B) and described methodological issues in some detail (e.g. method of randomisation, flow of participants, blinding of outcome assessment).

There were 19 IIT trials, 12 of which had a crossover design and seven a parallel design. Altogether, 7975 individuals participated in the IIT trials. Both treatment groups had an unweighted mean age of 36 years and a diabetes duration of 14 years. Trial duration ranged from 28 to 360 days, with a mean follow-up period of 122 days. The quality of 15 studies was assessed to be in category $\mathrm{C}$ and only three studies were of higher quality (category B).

Glycaemic control - HbAlc. Post-treatment $\mathrm{HbA}_{1} \mathrm{c}$ levels were assessed in 20 studies. The CSII and IIT studies were analysed separately. For studies using CSII (two parallel, five crossover), the weighted mean difference in $\mathrm{HbA}_{1} \mathrm{c}$ percentages between SAI analogues and regular insulin was $-0.19 \%$ (95\% CI: -0.27 to -0.12 ) (Fig. 2a), whereas for IIT studies (six parallel, seven crossover) the weighted mean difference in $\mathrm{HbA}_{1} \mathrm{c}$ percentages was $-0.08 \%(95 \%$ CI: -0.15 to -0.02 ) (Fig. 2b). Although the CSII studies showed no significant variation $(p=0.6)$, the chi square test showed some evidence of heterogeneity among the IIT studies $(p=0.09)$. The robustness of the results was evaluated using different statistical models. The estimates from the fixed-effects model were similar for both treatment regimens. The funnel plots did not indicate publication bias with Egger's test, yielding non-significant results for both types of administration ( $p=0.5$ for CSII, $p=0.8$ for IIT).

Hypoglycaemic episodes. Overall hypoglycaemic episodes were reported for 26 studies. However, only nine studies mentioned mean episodes per patient per month, which was the criterion used for analysis. For 

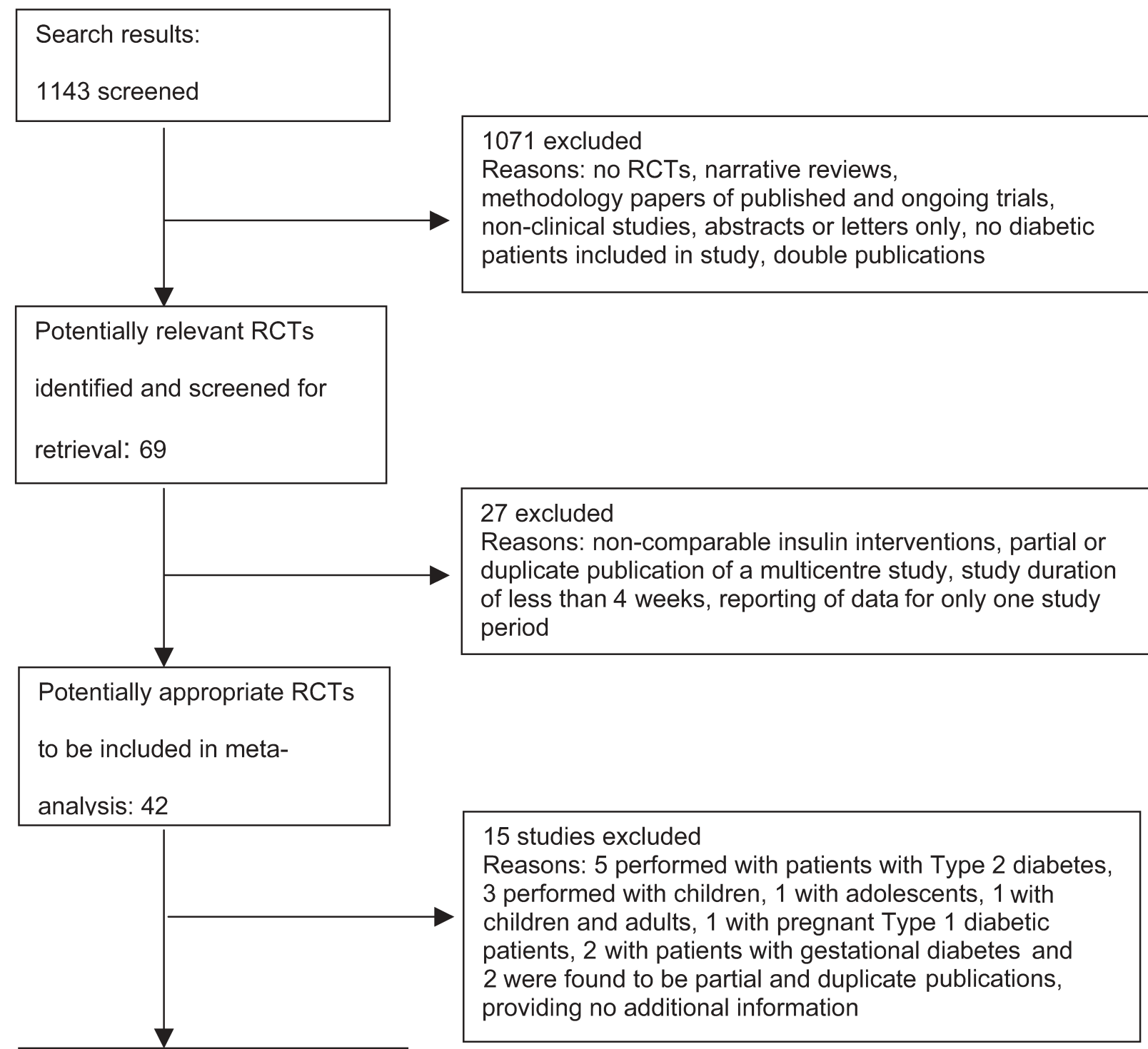

RCTs with usable information

included in meta-analysis: 27

Fig. 1. Flow chart showing the numbers of randomised controlled trials identified, those excluded for various reasons and those included in the meta-analysis. RCTs, randomised controlled trials

studies using CSII (one parallel, two crossover), the standardised mean difference between SAI analogues and regular insulin was -0.07 (95\% CI: -0.43 to 0.28 ) (Fig. 3a). For unstandardised data it is equivalent to 0.49 (95\% CI: -1.9 to 0.9 ). For IIT studies (two parallel, four crossover) the standardised mean difference was -0.04 (95\% CI: -0.24 to 0.16 ) (Fig. $3 b$ ). In original units it is equivalent to -0.06 (95\% CI: -1.28 to 1.16).
Severe hypoglycaemic episodes were reported for 22 studies. One study was excluded from analysis due to the use of different inclusion criteria compared with the other studies [41]. In this study, which only included patients with hypoglycaemic unawareness, there was a trend toward a lower number of severe hypoglycaemic events in the analogue group compared with the regular insulin group (55 vs 84 episodes respectively, $p=0.09$ ). For studies using CSII, the incidence of severe hypoglycaemia ranged from 0 to 21.8 (median 0) episodes per 100 person-years for SAI analogues and from 0 to 21.8 (median 5.5) episodes per 100 person-years for regular insulin. For studies using IIT, the incidence of severe hypoglycaemia ranged from 0 to 247.3 (median 33.3) episodes per 100 person-years for SAI analogues and from 0 to 544 (median 50.5) episodes per 100 person-years for regular insulin. 
a

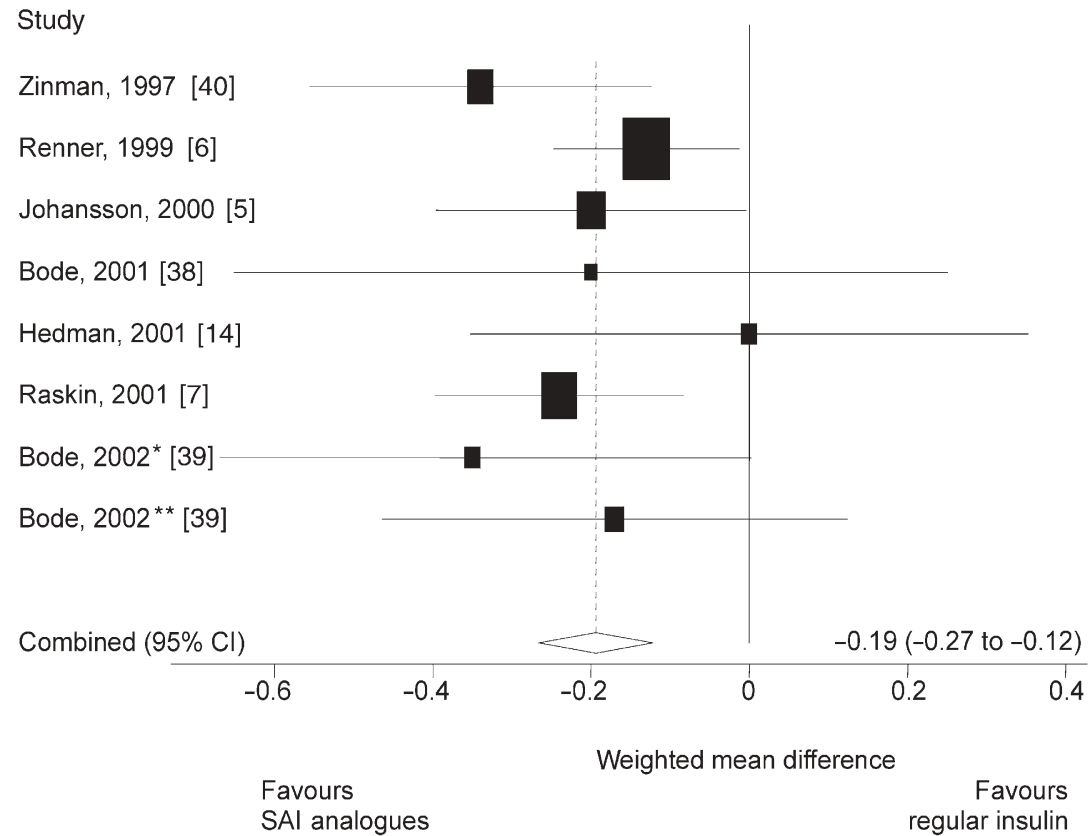

b

Study

Anderson, 1997 [12]

Anderson, 1997 [8]

Holleman, 1997 [10]

Vignati, 1997 [52]

Ciofetta, 1999 [47]

Gale, 2000 [16]

Home, 2000 [44]

Raskin, 2000 [49]

Annuzzi, 2001 [48]

Ferguson, 2001 [41]

Iwamoto, 2001 [45]

Provenzano, 2001 [46]

Recasens, 2003 [50]

Combined $(95 \% \mathrm{Cl})$

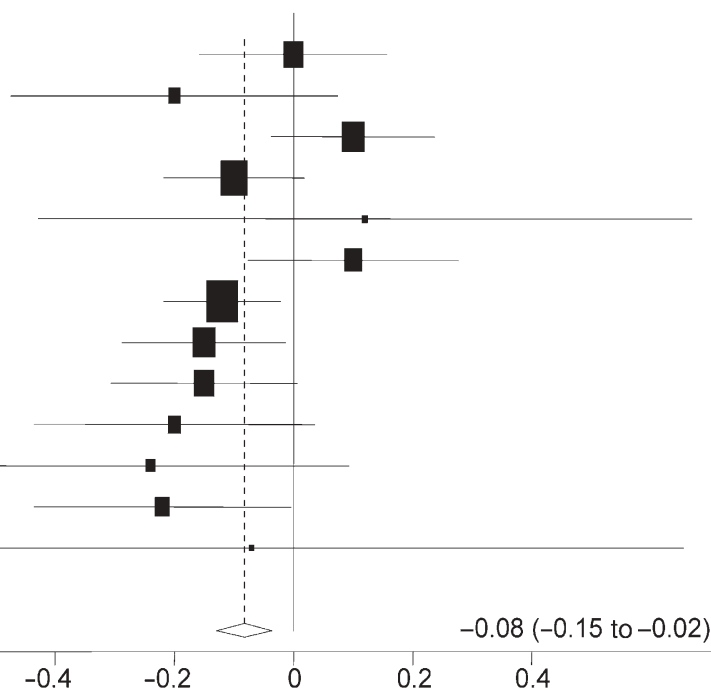

Favours

Weighted mean difference

$\mathrm{SAl}$ analogues

regular insulin

Fig. 2. Weighted mean differences $(95 \% \mathrm{CI})$ in $\mathrm{HbA}_{1} \mathrm{c}$ percentage values between SAI analogues and structurally unchanged short-acting insulin administered via (a) CSII or (b) IIT. * Aspart vs regular; ** lispro vs regular

\section{Discussion}

This meta-analysis includes 27 randomised controlled trials. In adults with type 1 diabetes the use of SAI analogues in CSII only produced a relatively small improvement in glycaemic control compared with regular insulin. This effect was negligible in patients in IIT studies. We did not differentiate between the SAI analogues lispro and aspart because it is known that both insulin analogues are equally effective at controlling prandial blood glucose fluctuations in type 1 diabetic patients $[55,56]$.

The heterogeneous design of the studies, often of poor methodological quality, only allows a cautious interpretation of the results to be made. In addition, only a small percentage of authors submitted the original data we requested, and therefore this communication process did not substantially improve the study quality 
a

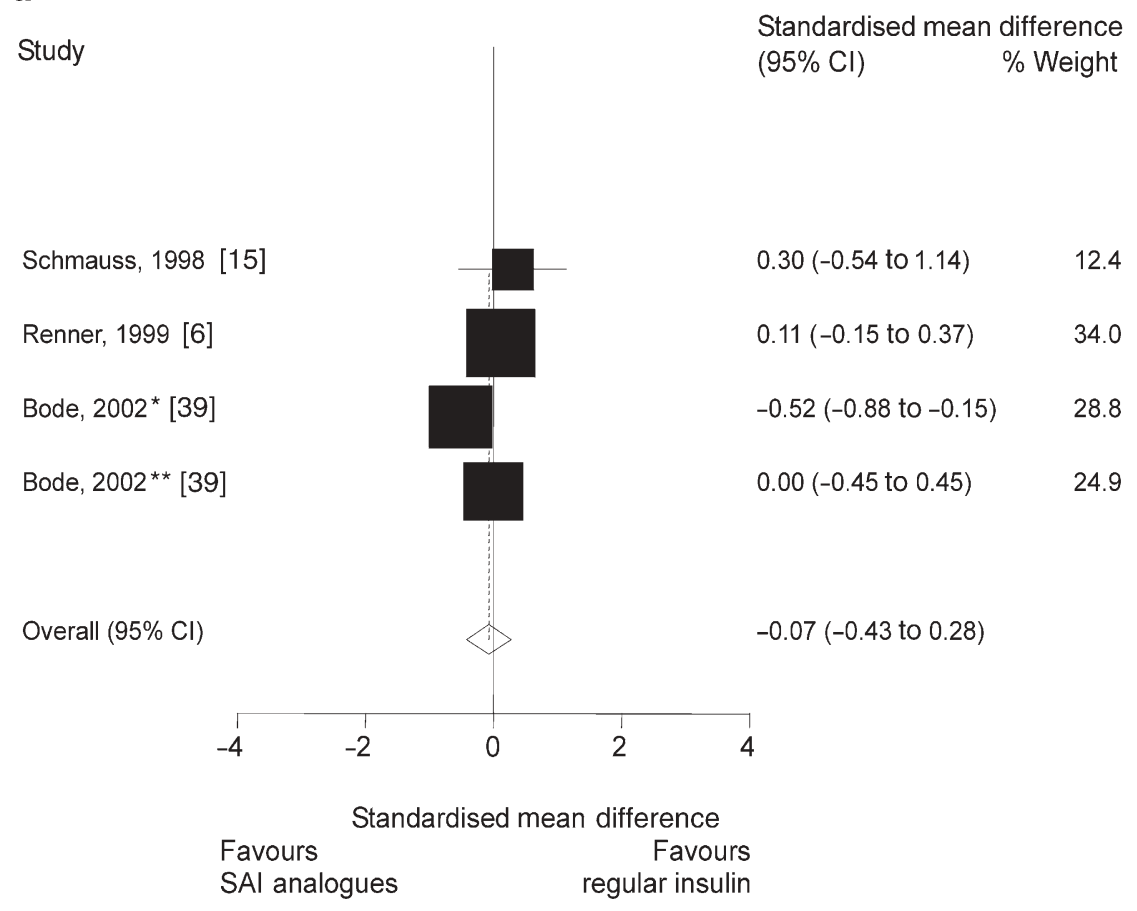

b

Study

Anderson, 1997 [12]

Anderson, 1997 [8]

Vignati, 1997 [52]

Del Sindaco, $1998^{* * *[11]}$

Del Sindaco, $1998^{\star \star \star *}[11]$

Ciofetta, 1999 [47]

Gale, 2000 [16]
Standardised mean difference

$(95 \% \mathrm{Cl}) \quad \%$ Weight
$-0.10(-0.19$ to -0.01$) \quad 25.6$

$-0.02(-0.23$ to 0.20$) \quad 20.7$

$0.02(-0.12$ to 0.16$) \quad 23.7$

$0.31(-0.41$ to 1.03$) \quad 6.1$

$-1.52(-2.44$ to -0.61$) \quad 4.1$

$2.17(0.90$ to 3.44$) \quad 2.3$

$-0.13(-0.42$ to 0.15$) \quad 17.4$

$-0.04(-0.24$ to 0.16$)$

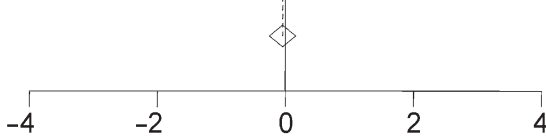

Standardised mean difference

Favours

SAl analogues

Fig. 3. Weighted mean differences $(95 \% \mathrm{CI})$ in overall hypoglycaemic event rates between SAI analogues and structurally unchanged short-acting insulin administered via (a) CSII or (b) IIT. * Aspart vs regular; ** lispro vs regular; *** lispro vs regular + neutral protamine Hagedorn insulin once or twice daily; $* * * *$ lispro vs regular + neutral protamine Hagedorn insulin four times daily
Favours assessment. According to the authors who replied, some did not have direct access to original data or did not complete our questionnaire due to lack of time and funding. Any further improvement of this meta-analysis can only be made with access to the original database.

In the DCCT, over a period of 6.5 years, a decrease in $\mathrm{HbA}_{1} \mathrm{c}$ of about $2 \%$ resulted in an absolute risk reduction of $20 \%$ for the development of retinopathy and of $17 \%$ for the progression of retinopathy, which yields numbers needed to treat per year of 32 and 39 
respectively [57]. Assuming that a reduction in $\mathrm{HbA}_{1} \mathrm{c}$ with insulin analogues would result in a similar relative benefit, 320 patients would have to be treated with SAI analogues in CSII for 1 year to prevent the development of retinopathy in one patient. Accordingly, 390 patients would need to be treated to prevent the progression of diabetic retinopathy in a single patient. For patients treated with SAI analogues in IIT, the numbers needed to treat per year would be 800 and 975 respectively. However, in the DCCT the beneficial effect of improved glycaemic control on microvascular complications was not seen until after 3 years of treatment [57]. SAI analogues have only been tested in short-term studies, and it is still uncertain whether this treatment will result in a significant longterm improvement in $\mathrm{HbA}_{1} \mathrm{c}$. Also, it remains unclear whether the beneficial effect of improved glycaemic control on the development and progression of microvascular complications achieved with regular insulin is equal to that obtained with SAI analogues [58].

As regards hypoglycaemic events, various studies reported these over different time intervals. The episodes were sometimes counted overall or per patient per month. The studies were also limited by the different definitions used for hypoglycaemic episodes. Some used glucose concentrations between $<2 \mathrm{mmol} / \mathrm{l}$ and $<3.9 \mathrm{mmol} / \mathrm{l}$, whilst others used symptoms of different severity from unwellness to coma. In terms of severe hypoglycaemic episodes, the definition ranged from third-party help to coma and/or application of glucagon or glucose. Therefore, heterogeneity between the trials only allows a statistical analysis of overall hypoglycaemic events to be made.

For overall hypoglycaemic episodes, the results of our analysis did not confirm the often postulated advantage of reduced hypoglycaemic events with SAI analogue treatment. There were no significant differences in overall hypoglycaemia between SAI analogues and regular insulin in either injection regimen. The estimation that an average type 1 diabetic patient experiences six to eight mild episodes of hypoglycaemia per month $[59,60]$ implies that the non-significant reduction of hypoglycaemic episodes with SAI analogues in CSII and IIT trials that was obtained in our meta-analysis was clinically negligible.

For severe hypoglycaemia, we expressed the number of overall episodes per 100 person-years in terms of medians and ranges. The more appropriate analysis of "the number of patients with at least one severe hypoglycaemic episode" was not possible because these data were only reported by a minority of studies. Our analysis does not take into account how the likelihood of hypoglycaemic events is influenced by factors such as social status, C-peptide levels or patients' determination to reach normoglycaemia [61, 62]. Severe hypoglycaemia occurred less often in CSII studies than in IIT studies for both agents. The wide range of values for severe hypoglycaemia in IIT studies was mostly the result of the inclusion of one study of very short duration [43]. In this study, the definition of severe hypoglycaemia was "third-party help", although the inclusion criteria for patients did not differ from the other studies analysed. The extraordinarily high number of severe hypoglycaemic episodes reported in this study may have been caused by the use of a strict dosage algorithm for hyperglycaemia and hypoglycaemia. In CSII studies and in IIT studies, the frequency of severe hypoglycaemia was lower in patients on SAI analogues. However, interpreting study results pertaining to the frequency of severe hypoglycaemia is difficult due to inconsistent and bias-prone definitions. Patients may inappropriately deny severe hypoglycaemia, and in this context "third-party help" is a soft and variable description of severity. More robust definitions, such as "injection of glucose or glucagon by another person" may produce more reliable data [62]. This definition of severe hypoglycaemia was used in only four studies, whereas five studies did not provide any definition of severe hypoglycaemia. Furthermore, based on the evidence available on this topic, it does not seem plausible that the frequency of severe hypoglycaemia can be reduced without a concomitant reduction in the frequency of overall hypoglycaemic episodes [63].

The frequency of nocturnal hypoglycaemia could not be analysed because in most cases the definition of nocturnal hypoglycaemia was either not reported, not defined or differed substantially between trials (e.g. 24.00-06.00 hours, median bedtime to median breakfast time, 23.00-06.00 hours, bedtime to 07.00 hours).

Taking into account the low quality of the trials included, our analysis suggests only a negligible benefit of SAI analogues in the majority of diabetic patients treated with insulin. We suggest a cautious response to the vigorous promotion of insulin analogues until long-term efficacy and safety data are available. More appropriately designed studies of longer duration would result in more robust findings. Because of the nature of the endpoints in studies investigating the effects of insulin treatment, such studies should be designed, performed and statistically analysed without any sponsoring bias.

Acknowledgements. The excellent technical assistance of $\mathrm{K}$. Bergerloff is acknowledged. We thank R. Gfrerer, K. Jeitler, P. Mrak, M. Narath, B. Semlitsch and R. Sommer for assistance in reviewing and collecting the data and C. Horvath for helping prepare the manuscript. We thank S. Neugebauer for the translation of the Japanese paper. This study was supported by grants from the Department of Internal Medicine, Medical University Hospital, Graz, Austria; the Institute for Medical Informatics, Statistics and Documentation, Karl-Franzens University, Graz, Austria; the Department of Internal Medicine, St. Franziskus Hospital and Institute for Evidence-based Medicine, Cologne, Germany; and Joanneum Research, Institute of Medical Technologies and Health Management, Graz, Austria.

\section{Contribution of reviewers:}

A. Siebenhofer: protocol development, quality assessment of trials, data extraction, development of final review, corresponding author 
J. Plank: searching for trials, administration and correspondence, quality assessment of trials, data extraction, development of final review

A. Berghold: protocol development, data analysis, development of final review

Karl Horvath: searching for trials, quality assessment of trials, data extraction, development of final review

P.T. Sawicki: correspondence, quality assessment of trials, data extraction, development of final review

P. Beck: data management, searching for trials, administration and correspondence, development of final review

T.R. Pieber: protocol development, quality assessment of trials, data analysis, development of final review

\section{References}

1. Zinman B (1989) The physiological replacement of insulin. An elusive goal. N Engl J Med 321:363-370

2. Mosekilde E, Jensen KS, Binder C, Pramming S, Thorsteinsson B (1989) Modeling absorption kinetics of subcutaneous injected soluble insulin. J Pharmacokinet Biopharm 17:67-87

3. Howey DC, Bowsher RR, Brunelle RL, Woodworth JR (1994) [Lys(B28), Pro(B29)]-human insulin. A rapidly absorbed analogue of human insulin. Diabetes 43:396-402

4. Torlone E, Fanelli C, Rambotti AM et al. (1994) Pharmacokinetics, pharmacodynamics and glucose counterregulation following subcutaneous injection of the monomeric insulin analogue [Lys(B28), Pro(B29)] in IDDM. Diabetologia 37:713-720

5. Johansson UB, Adamson UCK, Lins PES, Wredling RAM (2000) Improved blood glucose variability, HbA1c Insuman Infusat and less insulin requirement in IDDM patients using insulin lispro in CSII. The Swedish Multicenter Lispro Insulin Study. Diabetes Metab 26:192-196

6. Renner R, Pfutzner A, Trautmann M, Harzer O, Sauter K, Landgraf R (1999) Use of insulin lispro in continuous subcutaneous insulin infusion treatment. Results of a multicenter trial. German Humalog-CSII Study Group. Diabetes Care 22:784-788

7. Raskin P, Holcombe JH, Tamborlane WV et al. (2001) A comparison of insulin lispro and buffered regular human insulin administered via continuous subcutaneous insulin infusion pump. J Diab Compl 15:295-300

8. Anderson JH, Brunelle RL, Koivisto VA, Trautmann ME, Vignati L, DiMarchi R (1997) Improved mealtime treatment of diabetes mellitus using an insulin analogue. Multicenter Insulin Lispro Study Group. Clin Therap 19:62-72

9. Garg SK, Carmain JA, Braddy KC et al. (1996) Pre-meal insulin analogue insulin lispro vs Humulin $\mathrm{R}$ insulin treatment in young subjects with Type 1 diabetes. Diabet Med 13:47-52

10. Holleman F, Schmitt H, Rottiers R, Rees A, Symanowski S, Anderson JH (1997) Reduced frequency of severe hypoglycemia and coma in well-controlled IDDM patients treated with insulin lispro. The Benelux-UK Insulin Lispro Study Group. Diabetes Care 20:1827-1832

11. Del Sindaco P, Ciofetta M, Lalli C et al. (1998) Use of the short-acting insulin analogue lispro in intensive treatment of Type 1 diabetes mellitus: importance of appropriate replacement of basal insulin and time-interval injection-meal. Diabet Med 15:592-600

12. Anderson JH, Brunelle RL, Koivisto VA et al. (1997) Reduction of postprandial hyperglycemia and frequency of hypoglycemia in IDDM patients on insulin-analog treatment. Multicenter Insulin Lispro Study Group. Diabetes 46:265-270
13. Pfutzner A, Kustner E, Forst T et al. (1996) Intensive insulin therapy with insulin lispro in patients with type 1 diabetes reduces the frequency of hypoglycemic episodes. Exp Clin Endocrinol Diabetes 104:25-30

14. Hedman CA, Orre-Pettersson AC, Lindstrom T, Arnquist HJ (2001) Treatment with insulin lispro changes the insulin profile but does not affect the plasma concentrations of IGF-I and IGFBP-1 in type 1 diabetes. Clin Endocrinol 55:107-112

15. Schmauss S, Konig A, Landgraf R (1998) Human insulin analogue [Lys(B28), Pro(B29)]: the ideal pump insulin? Diabet Med 15:247-249

16. Gale EA (2000) A randomized, controlled trial comparing insulin lispro with human soluble insulin in patients with Type 1 diabetes on intensified insulin therapy. The UK Trial Group. Diabet Med 17:209-214

17. Moher D, Cook DJ, Eastwood S, Olkin I, Rennie D, Stroup DF (1999) Improving the quality of reports of meta-analysis of randomised controlled trials: the QUOROM statement. Lancet 354:1896-1900

18. The Cochrane Library (2003) Issue 4. Oxford: Update Software

19. Jadad AR, Moore RA, Carroll D et al. (1996) Assessing the quality of reports of randomized clinical trials: is blinding necessary? Control Clin Trials 17:1-12

20. Schulz KF, Chalmers I, Hayes RJ, Altman DG (1995) Empirical evidence of bias: dimensions of methodological quality associated with estimates of treatment effects in controlled trials. JAMA 273:408-412

21. Elbourne DR, Altman DG, Higgins JPT, Curtin F, Worthington HV, Vail A (2002) Meta-analyses involving cross-over trials: methodological issues. Int $\mathrm{J}$ Epidemiol 31:140-149

22. Curtin F, Altman DG, Elbourne DR (2002) Meta-analysis combining parallel and cross-over clinical trials. I: continuous outcomes. Stat Med 21:2131-2144

23. Anderson JH Jr, Brunelle RL, Keohane P et al. (1997) Mealtime treatment with insulin analog improves postprandial hyperglycemia and hypoglycemia in patients with noninsulin-dependent diabetes mellitus. Arch Int Med 157: 1249-1255

24. Roach P, Yue L, Arora V (1999) Improved postprandial glycemic control during treatment with Humalog Mix25, a novel protamine-based insulin lispro formulation. Humalog Mix25 Study Group. Diabetes Care 22:1258-1261

25. Ross SA, Zinman B, Campos RV, Strack T (2001) A comparative study of insulin lispro and human regular insulin in patients with type 2 diabetes mellitus and secondary failure of oral hypoglycemic agents. Clin Invest Med 24:292-298

26. Herz M, Profozic V, Arora V et al. (2002) Effects of a fixed mixture of $25 \%$ insulin lispro and $75 \%$ NPL on plasma glucose during and after moderate physical exercise in patients with type 2 diabetes. Curr Med Res Opin 18:188-193

27. Herz M, Arora V, Campaigne BN, Scholtz HE, Potgieter MA, Mollentze W (2003) Humalog Mix 25 improves 24hour profiles compared with the human insulin mixture $30 / 70$ in patients with type 2 diabetes mellitus. S Afr Med J 93:219-223

28. Deeb LC, Holcombe JH, Brunelle R et al. (2001) Insulin lispro lowers postprandial glucose in prepubertal children with diabetes Pediatrics 108:1175-1179

29. Tupola S, Komulainen J, Jaaskelainen J, Sipila I (2001) Post-prandial insulin lispro vs. human regular insulin in prepubertal children with type 1 diabetes mellitus. Diabet Med 18:654-658

30. Ford-Adams ME, Murphy NP, Mooore EJ et al. (2003) Insulin lispro: a potential role in preventing nocturnal hypo- 
glycaemia in young children with diabetes mellitus. Diabet Med 20:656-660

31. Holcombe JH, Zalani S, Arora VK, Mast CJ; Lispro in Adolescents Study Group (2002) Comparison of insulin lispro with regular human insulin for the treatment of type 1 diabetes in adolescents. Clin Ther 24:629-638

32. Jacobs MA, Keulen ET, Kanc K, Casteleijn S, Scheffer P, Deville W, Heine R (1997) Metabolic efficacy of preprandial administration of Lys(B28), Pro(B29) human insulin analog in IDDM patients: a comparison with human regular insulin during a three-meal test period. Diabetes Care 20:1279-1286

33. Persson B, Swahn ML, Hjertberg R et al. (2002) Insulin lispro therapy in pregnancies complicated by type 1 diabetes mellitus. Diabetes Res Clin Pract 58:115-121

34. Jovanovic L, Ilic S, Pettitt DJ et al. (1999) Metabolic and immunologic effects of insulin lispro in gestational diabetes. Diabetes Care 22:1422-1427

35. Mecacci F, Carignani L, Cioni R et al. (2003) Maternal metabolic control and perinatal outcome in women with gestational diabetes treated with regular or lispro insulin: comparison with non-diabetic pregnant women. Eur J Obstet Gynecol Reprod Biol 111:19-24

36. Kotsanos JG, Vignati L, Huster L et al. (1997) Health-related quality-of-life results from multinational clinical trials of insulin lispro. Diabetes Care 20:948-958

37. Bott U, Ebrahim S, Hirschberger S, Skovlund SE (2003) Effect of the rapid-acting insulin analogue insulin aspart on the quality of life treatment satisfaction in patients with Type 1 diabetes. Diabet Med 20:626-634

38. Bode BW, Strange P (2001) Efficacy, safety, and pump compatibility of insulin aspart used in continuous subcutaneous insulin infusion therapy in patients with type 1 diabetes. Diabetes Care 24:69-72

39. Bode B, Weinstein R, Bell D et al. (2002) Comparison of insulin aspart with buffered regular insulin and insulin lispro in continuous subcutaneous insulin infusion. Diabetes Care 25:439-444

40. Zinman B, Tildesley H, Chiasson JL et al. (1997) Insulin lispro in CSII: results of a double-blind crossover study. Diabetes 46:440-443

41. Ferguson SC, Strachan MWJ, Janes JM, Frier BM (2001) Severe hypoglycaemia in patients with type 1 diabetes and impaired awareness of hypoglycaemia: a comparative study of insulin lispro and regular human insulin. Diabetes Metab Res Rev 17:285-291

42. Heller SR, Amniel SA, Mansell P (1999) Effect of the fastacting insulin analog lispro on the risk of nocturnal hypoglycemia during intensified insulin therapy. UK Lispro Study Group. Diabetes Care 22:1607-1611

43. Home PD, Lindholm A, Hylleberg B, Round P (1998) Improved glycemic control with insulin aspart: a multicenter randomized double-blind crossover trial in type 1 diabetic patients. UK Insulin Aspart Study Group. Diabetes Care 21:1904-1909

44. Home PD, Lindholm A, Riis A (2000) European Insulin Study Group. Insulin aspart vs. human insulin in the management of long-term blood glucose control in Type 1 diabetes mellitus: a randomized controlled trial. Diabet Med 17:762-770

45. Iwamoto Y, Akanuma Y, Niimi H, Sasaki N, Tajima N, Kawamori R (2001) Comparison between insulin aspart and soluble human insulin in type 1 diabetes (IDDM) patients treated with basal-bolus insulin therapy-Phase III clinical trial in Japan. J Jpn Diabetes Soc 44:799-811

46. Provenzano C, Vero R, Oliva A et al. (2001) Lispro insulin in Type 1 diabetic patients on a Mediterranean or normal diet: a randomized, cross-over comparative study with regular insulin. Diabetes Nutr Metab 14:133-139

47. Ciofetta M, Lalli C, Del Sindaco P et al. (1999) Contribution of postprandial versus interprandial blood glucose to HbA1c in type 1 diabetes on physiologic intensive therapy with lispro insulin at mealtime. Diabetes Care 22: 795-800

48. Annuzzi G, Del Prato S, Arcari R et al. (2001) Preprandial combination of lispro and NPH insulin improves overall blood glucose control in type 1 diabetic patients: a multicenter randomized crossover trial. Nutr Metab Cardiovasc Dis 11:168-175

49. Raskin P, Guthrie RA, Leiter L, Riis A, Jovanovic L (2000) Use of insulin aspart, a fast-acting insulin analog, as the mealtime insulin in the management of patients with type 1 diabetes. Diabetes Care 23:583-588

50. Recasens M, Aguilera E, Morinigo R et al. (2003) Insulin lispro is as effective as regular insulin in optimising metabolic control and preserving beta-cell function at onset of type 1 diabetes mellitus. Diab Res Clin Pract 60:153-159

51. Roach P, Trautmann M, Arora V, Sun B, Anderson JH Jr, Haslbeck M (1999) Improved postprandial blood glucose control and reduced nocturnal hypoglycemia during treatment with two novel insulin lispro-protamine formulations, insulin lispro Mix25 and insulin lispro Mix50. Mix50 Study group. Clin Ther 21:523-534

52. Vignati L, Anderson JH Jr, Iversen PW (1997) Efficacy of insulin lispro in combination with NPH human insulin twice per day in patients with insulin-dependent or non-insulin-dependent diabetes mellitus. Multicenter Insulin Lispro Study Group. Clin Ther 19:1408-1421

53. Boehm BO, Home PD, Behrend C, Kamp NM, Lindholm A (2002) Premixed insulin aspart 30 vs. premixed human insulin 30/70 twice daily: a randomized trial in type 1 and type 2 diabetic patients. Diabet Med 19:393-399

54. Skrha J, Smahelova A, Andel M et al. (2002) Insulin lispro improves postprandial glucose control in patients with diabetes mellitus. Sb Lek 103:15-21

55. Plank J, Wutte A, Brunner G et al. (2002) A direct comparison of insulin aspart and insulin lispro in patients with type 1 diabetes. Diabetes Care 25:2053-2057

56. Homko C, Deluzio A, Jimenez C, Kolaczynski JW, Boden G (2003) Comparison of insulin aspart and lispro. Diabetes Care 26:2027-2031

57. The Diabetes Control and Complications Trial Research Group (1993) The effect of intensive treatment of diabetes on the development and progression of long-term complications in insulin-dependent diabetes mellitus. N Engl J Med 329:977-986

58. Owens DR, Zinman B, Bolli GB (2001) Insulins today and beyond. Lancet 358:739-746

59. Pramming S, Thorsteinsson B, Bendtson I, Binder C (1990) The relationship between symptomatic and biochemical hypoglycemia in insulin-dependent diabetic patients. J Int Med 228:641-646

60. The DCCT Research Group (1991) Epidemiology of severe hypoglycemia in the Diabetes Control and Complications Trial. Am J Med 90:450-459

61. Windeler J, Lange S (1995) Events per person year-a dubious concept. BMJ 310:454-456

62. Mühlhauser I, Overmann H, Bender R, Bott U, Berger M (1998) Risk factors of severe hypoglycaemia in adult patients with Type 1 diabetes - a prospective population based study. Diabetologia 41:1274-1282

63. Cryer PE (2002) Hypoglycaemia the limiting factor in the glycaemic management of Type I and Type II diabetes. Diabetologia 45:937-948 